\title{
Analysis of runoff in the Han River basin by SSARR model considering agricultural water
}

\author{
Sang-Jin Lee $\cdot$ Seung-Jin Maeng $\cdot$ Hyung-San Kim $\cdot$ \\ Sang-Il Na
}

Received: 2 August 2010/Revised: 9 April 2011/Accepted: 22 May 2011/Published online: 10 June 2011

(C) The Author(s) 2011. This article is published with open access at Springerlink.com

\begin{abstract}
This study begins to address the need for a runoff model that is able to simulate runoffs at control points in a dam's upper and lower stream during the seasons of high and low water levels. We need to establish a synthetic management plan on water resources considering the runoff at the upper and lower streams to effectively manage the limited water resources in Korea. For this reason, we classified the Han River Basin into 24 subbasins and arranged a great amount of rainfall data using 151 rainfall observation stations so as to prepare for the spatial distribution of precipitation. We chose several dams as subjects for this study, which includes the Chungju Regulating Reservoir, Soyang, Chungju, Hoengseong, Hwacheon, Chuncheon, Euiam, Cheongpyeong, and Paldang Dams as main controlling points. Also, we made up input data of this model, selecting the Streamflow Synthesis and Reservoir Regulation (SSARR) model as a runoff model in the Han River Basin. We performed a sensitivity analysis of parameters using hydrological data from the year 2002. And as a result, the findings of this study showed that, among many parameters related to the basin runoff, the following have revealed greater sensitivity than any other parameters: soil moisture index-runoff
\end{abstract}

\section{S.-J. Lee}

Korea Institute of Water and Environment, Korea Water Resources Corporation, 462-1 Jeonmin-dong, Yuseong-gu, Daejeon 305-730, South Korea

\section{S.-J. Maeng $(\bowtie) \cdot$ H.-S. Kim · S.-I. Na}

Department of Agricultural and Rural Engineering, Chungbuk National University, 12 Gaesin-dong, Heungdeok-gu, Cheongju, Chungbuk 361-763, South Korea

e-mail: maeng@chungbuk.ac.kr percent, baseflow infiltration index-baseflow percent, and surface-subsurface separation. On the basis of the above sensitivity analysis, we have used hydrological data between 2001 and 2002 when drafts and floods broke out in Korea to verify and calibrate the parameters of the SSARR model. Furthermore, we verified and calibrated the 2000 data using corrected parameters and performed an analysis of annual water balance in the Han River Basin from 1996 to 2005 considering agricultural water.

Keywords Dam · Rainfall - Runoff · Control point · Sensitivity analysis $\cdot$ SSARR model $\cdot$ Water resources management

\section{Introduction}

Recently, frequent floods and drafts due to rapid weather change and sharply increasing demand for water have aggravated our use of the environment and of the available water resources. For this reason, it is necessary to develop new water resources. However, developing artificial water resources has become difficult due to the spreading environmentalist idea against the expensive construction of dams. According to this, "continuous development" has become the alternative to meet present needs, but this undermines the capacity to meet the needs of future generations. Now, we have to make use of available resources by simply improving the operations of existing dams, which turns the existing supply oriented management into a demand-oriented management for the concept of water resources. Under present circumstances, Korea has to develop new water resources to prepare for possible drafts and floods due to future increase in water demand and rapid climate change. But, the effective management of existing 
dams has become the primary step in managing the water resources of the country and now all bets for the construction of the Youngwol dam are off. Therefore, we have to assure the continuous availability of water resources as well as the enlargement of flood control by way of turning them around. In other words, we must increase water supply by improving operation methods, and at the same time control the possible increase of water demand by means of an effective water demand management.

One of the best solutions for this is the maximization of existing water resources through a joint operation of dam groups from the same hydrosphere. In order to establish a joint operating plan for these dam groups, a model is required to simulate the runoff in the hydrosphere. A model to simulate the hydrosphere runoff has already been made for the Geum River Basin, while those for other basins have not been successful. Korea's long-term runoff model has widely used the Tank model (Sugawara 1979) developed in Japan, whose basin environment is very similar to that in Korea (Kim and Park 1988; Park 1993). We have recently attempted to confirm the applicability of the model that can consider soil moisture. Such models that have been tested were the Streamflow Synthesis and Reservoir Regulation (SSARR) (U.S. Army Corps of Engineers 1991) and National Weather Service River Forecast System (NWSRFS) models. However, NWSRFS is not easy to improve because of its characteristic as a black box and it does not have an operating function (National Weather Service 1996). It is suitable for the hydrological forecasting in case of floods due to the limitation of time intervals.

This study selected the SSARR model as a model for long-term runoff analysis in the Han River Basin, considering the climate and topographical characteristics of the basin including the quality and quantity of input data. The SSARR model has been successfully applied to big rivers such as the Columbia River in the United States (Nelson and Rockwood 1971) and the Mekong River in Vietnam (Rockwood 1968). In Korea, this model has been applied to the Han River Basin (KOWACO 2000, 2008), the Nakdong River (KOWACO 1996), the Bocheongcheon Basin of the Geum River (An and Lee 1989), and Geum River Basins (KOWACO 2004; Hwang et al. 2009).

As a lumped parameter model, the SSARR model can be of optimal value through trial and error for 11 parameters. It can simulate the runoff amount of both rainfalls and snowfalls. Therefore, this study constructed a runoff system that can simulate the entire Han River Basin using the SSARR model, performing the sensitivity analysis, verification, and calibration for the parameters of the SSARR model selected as a basic model that is best suited for the Han River Basin.

\section{Methods and materials}

Theoretical concept of the SSARR model

The SSARR model was first developed in 1956 as a mathematical and hydrological model for planning, designing, and managing water resources systems in the North Pacific Division of the U.S Army Corps of Engineers (USACE 1991).

The SSARR model has two versions: the Depletion Curve (DC) version model and the Integrated Snowband (IS) version model. This study uses the IS version model, which has complemented functions useful for long-term runoffs such as routing functions in lower zones and in low-flow runoff simulation and evapotranspiration functions. The SSARRIS model performs runoff interpretations, dividing the basin concerned into 1-20 bands according to altitude, precipitation, soil moisture, and changes in evapotranspiration according to the temperature.

This method focuses on the fact that there is a difference between the amount of snow and water in soil according to altitude, and it usually divides the band into some in an interval of $600 \mathrm{~m}$. The SSARR runoff simulation system is largely composed of input, snow melt, water in soil, and runoff. The process of runoff interpretations is as follows:

First, it calculates precipitation and temperature for each band from rainfall and within the basin or in nearby observatories.

Next, it classifies the data concerned into rainfall and snowfall according to the temperature of the day for each band except the loss by interceptions. For of rainfalls, it immediately moves into the earth surface where there are no snowdrifts. For snowfalls, it adds to the existing snowdrifts or forms new snowdrifts where there were no snowdrifts before. If there is any snowdrift, snowmelt by precipitation or by temperature comes out according to the amount of precipitation amount, and the water from the snowmelt moves into the soil. The sum of precipitations and snowmelts is divided into soil water and runoff according to Soil Moisture Index (SMI). The SMI measures the rate of runoff according to the condition of the soil. The SMI does not contribute to the runoff because soil water disappears only by evapotranspiration. The runoff amount can be classified into direct runoff and baseflow by baseflow infiltration index (BII). According to surfacesubsurface separation (S-SS), direct runoffs can be classified as either "above-surface runoff" or "below-surface runoff." And, according to lower zone (LZ), baseflow runoffs can be classified either "underwater runoff" or "return underwater runoff." Each runoff component moves into the reservoir as forms of surface water, subsurface water, baseflow and LZ, and then independently moves into river channels through a reservoir-tracing method. The 
sum of runoff is calculated into the runoff amount of rivers

(Fig. 1).

Basin applied and the division of the area owned

The Han River Basin is the greatest basin in Korea, which is 25,702.6- $\mathrm{km}^{2}$ wide and 494.4-km long. We divided the Han River Basin into 24 areas as shown in Fig. 2, considering the Chungju Regulating Reservoir, Chungju, Hoengseong, Soyang, Hwacheon, Chuncheon, Euiam, Cheongpyeong, and Paldang Dams as a whole according to the Report on the Long-term Comprehensive Plan on Water Resources (MOCT 2004a), the Survey Report on Water Supply Ability in Dams (KOWACO 1997), the Survey Report on the Han River Basin (MOCT 2004b), and the Mid-term and Longterm Synthetic Disaster Prevention Plan (MOC 1988).
Fig. 1 Diagram of the SSARR model (USACE 1991)

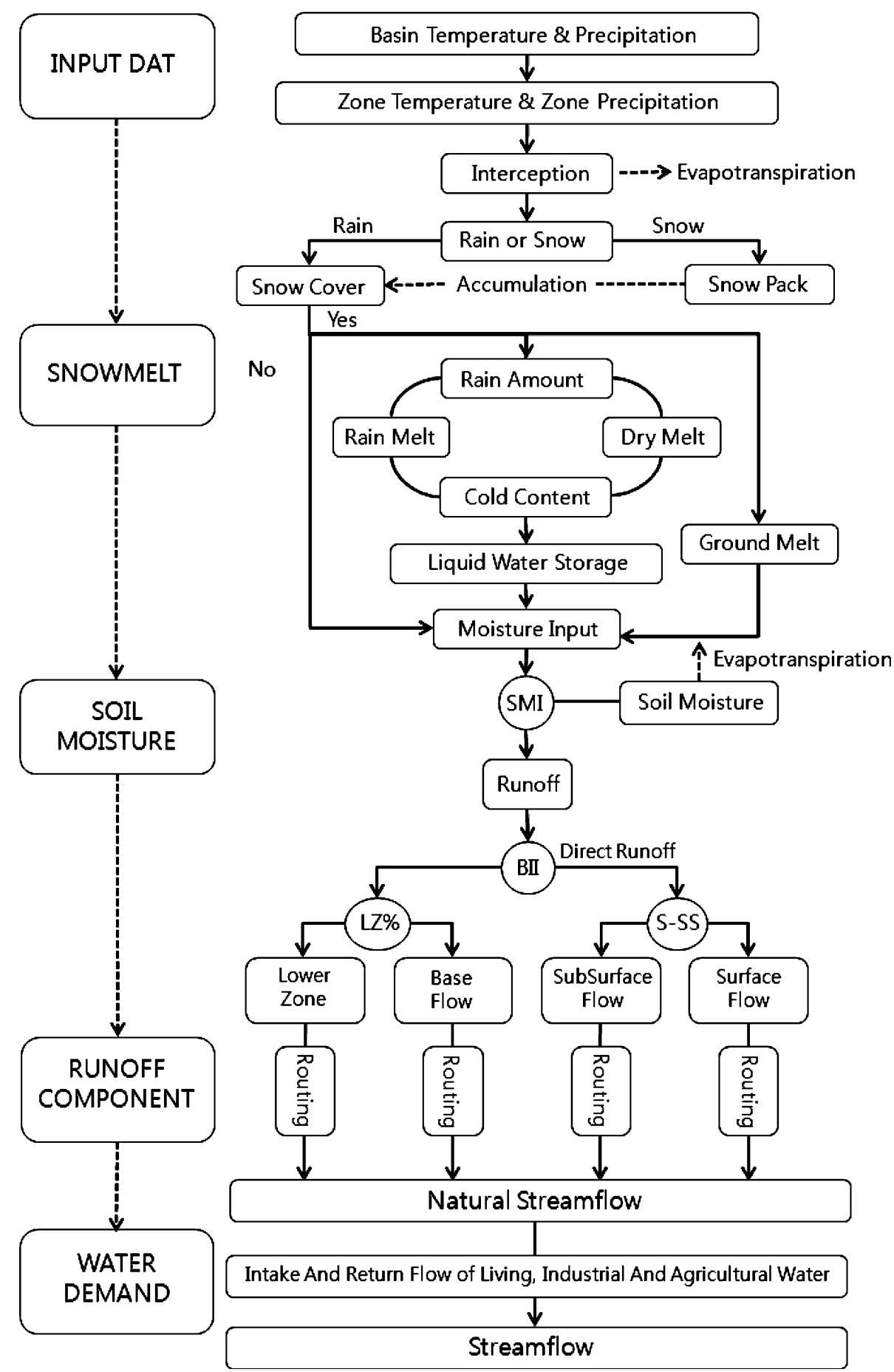


Fig. 2 Sub-basin distribution in the Han River

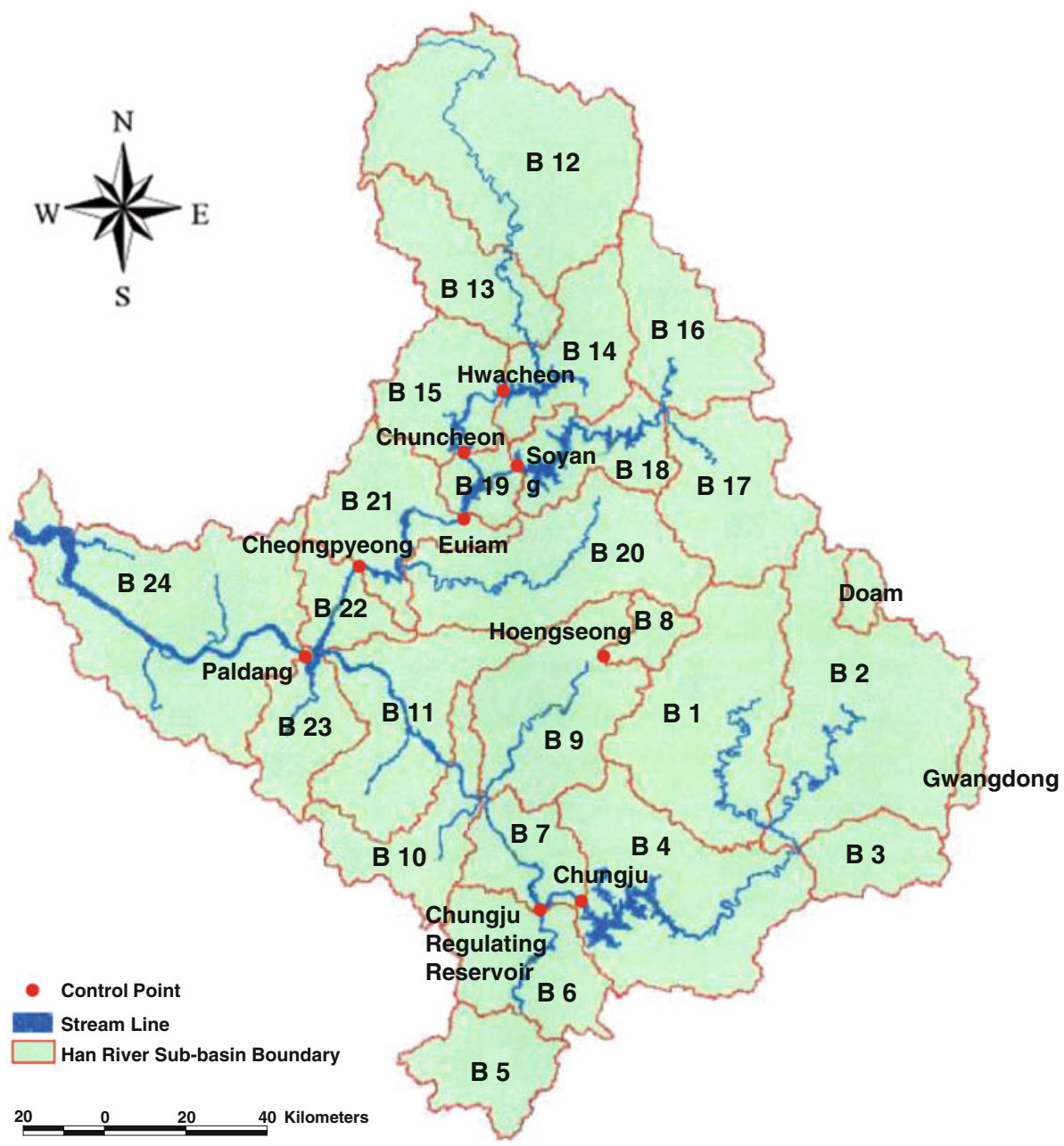

Precipitation for each sub-basin and area ratio for each altitude

In conjunction with this study, We selected precipitation observatories necessary for analyzing the runoff at the Chungju Regulating Reservoir, Soyang, Chungju, Hoengseong, Hwacheon, Chuncheon, Euiam, Cheongpyeong, and Paldang Dams in the Han River Basin, and 24 outlet areas on the basis of 151 precipitation observatories: 91 observatories governed by the Ministry of Construction and Transportation, 11 by the Korea Meteorological Administration and 49 by the Korea Water Resources Corporation. The average precipitation per day for each area was calculated by the Thiessen coefficient in each precipitation observatory selected.

In the SSARR-IS model, a precipitation-runoff model for the runoff simulation, rate of size of each elevation for each sub-basin area will be used as input data. The size and rate of size of the basin for each sub-basin area according to elevation were calculated by a GIS tool, ArcView 3.2 using a division map of the areas in the Han River Basin, which was made as forms of Digital Elevation Map (DEM) and Shp files.

Water data and return flow rate include agricultural water

Unlike some rainfall-runoff models, SSARR model has advantage that can simulate considering the living, industrial, and agricultural water. Specially, it is agricultural water above $50 \%$ of total water duty in Korea. Processing calibration of SSARR model, agricultural water and its return rate flow are important input data to estimate of simulated runoff using SSARR model.

We rearranged the water data used from the Han River Basin for each sub-basin area considering the Survey Report in the Han River Basin, and applied the data presented in the Survey Report from the Han River Basin as a return flow rate of water duty (MOCT 2004b). Specifically, we considered $80 \%$ of the return flow rate of water used for daily living necessities, $60 \%$ of industrial water, and $35 \%$ of agricultural water (including paddies and irrigation 
water) from March to August and 70\% from September to November. The distribution diagram for living, industrial, and agricultural water in the Han River Basin is shown in Fig. 3.

\section{Results and discussion}

Parameters of the SSARR model and calculation of the reference value

The parameters of the SSARR model consist of soil moisture index-runoff percentage (SMI-ROP), baseflow infiltration index-baseflow percentage (BII-BFP), surfacesubsurface separation (S-SS), BII's detention storage time, related to BII (BIITS), maximum BII (BIIMX), maximum subsurface runoff rate, BFLIM and percentage of total baseflow going to the LZ routing (PBLZ), whereas the parameters of the basin routing consist of surface flow, subsurface flow, baseflow, and baseflow going to the LZ routing. The parameters of river channel routing are $n$ and KTS in Eq. 1.

$T_{\mathrm{s}}=\frac{\mathrm{KTS}}{I^{n}}$

where KTS is a constant that is determined by trial and error, $I$ is a flow, and $n$ is a coefficient, which has a value between -1 and 1 . In order to analyze the sensitivity of parameters, we picked up the reference values of each parameter as shown in Table 1 referring to the SSARR manual (USACE 1991).

Sensitivity analysis of the parameters

The sub-basin selected for the sensitivity analysis of the Han River Basin is Number 17, which is close to the average of the whole in terms of sub-basin size and value of the curve number $(\mathrm{CN})$. Hydrological data used in this analysis are for a month before and after the maximum flow in the year 2002, when drafts and floods broke out at the same time.

The analysis was performed for the scope of the parameters for the sensitivity analysis in reference to the SSARR manual. In the SMI-ROP curve, sensitivity analysis was performed for the increased curve (SMI3) or decreased (SMI)10\%, respectively, from the reference value (SMI2); in the BII-BFP curve, an analysis for the value that was increased (BII3) or decreased (BII1) $10 \%$, respectively, was performed only where the value of BII was 0 (BII1); in the S-SS curve, an analysis for the value that was increased $(\mathrm{S}-\mathrm{SS} 3)$ or decreased $(\mathrm{S}-\mathrm{SS} 1) 0.15 \mathrm{~cm} / \mathrm{h}$, respectively, was performed from the reference value (S-SS2).
We indicated the reference value, scope, and sensitivity of all the parameters related to the runoff in the basin as seen in Table 2. We also selected a peak flow at high water level and the flow in the time (17 days shortly after the inflection point) when the direct runoff ends in low water level an index flow of sensitivity. Here, the sensitivity is defined as a geometric mean of flow change for the increased and decreased amount of parameters, as in Eq. 2.

$\sqrt{\frac{\left[\frac{\left(Q_{u}-Q_{o}\right) / Q_{o}}{\left(P_{u}-P_{o}\right) / P_{o}}\right]^{2}+\left[\frac{\left(Q_{o}-Q_{l}\right) / Q_{o}}{\left(P_{o}-P_{l}\right) / P_{o}}\right]^{2}}{2}}$

where $Q$ and $P$ are mean flow and the value of parameters, respectively; and $o, u$, and $l$ are mean index value, maximum value, and minimum value, respectively.

According to sensitivity analysis of the SMI1 and SMI3 curve compared with the SMI2 curve in Table 2, it is believed that the runoff rate for each soil moisture condition is one of the most important parameters despite the limited coordination of the peak flow and total flow through this parameter. The baseflow inflow rate for each infiltration amount is a parameter that sets the inflow ratio into the baseflow among the total runoff amount. Analysis results shown in Table 2 indicate that the sensitivity at high water level is greater than that at low water level. Therefore, it is somewhat possible to complement the flow at a low water level. According to the results of change in parameters for the S-SS, we believe that it would be possible to control the peak flow and total runoff amount using this parameter because there is a more sensitive change than in any other parameters in peak flow and the flow at low water level. However, there would be a limitation here. Parameters related to BII are BIITS and BFLIM. As shown in Table 2, it indicates insensitive results at low water level as well as at a high water level. The parameter of the percentage of total baseflow going to LZ routing means the rate of underground out-flow after a comparatively long time accounts for the whole baseflow. This parameter shows sharp changes in terms of the flow at low water level as shown in Table 2, even though it affects little on the peak flow. According to the percentage of the total baseflow going to LZ routing, baseflow runoff contributing to a groundwater DC formed shortly after peak flow decreases. Then, the decreased flow runs off afterward over a long period of time.

Basin routing parameters consist of the number of possible reservoirs and storage time for four flows: surface, subsurface, baseflow, and LZ. These parameters must be calculated differently according to the size of the basin, average surface runoff distance and slope, delayed time, land use and soil condition. These are usually determined by the sensitivity analysis and trial-and-error method. The values determined at two points in the United States 
Fig. 3 Distribution diagram for runoff simulation

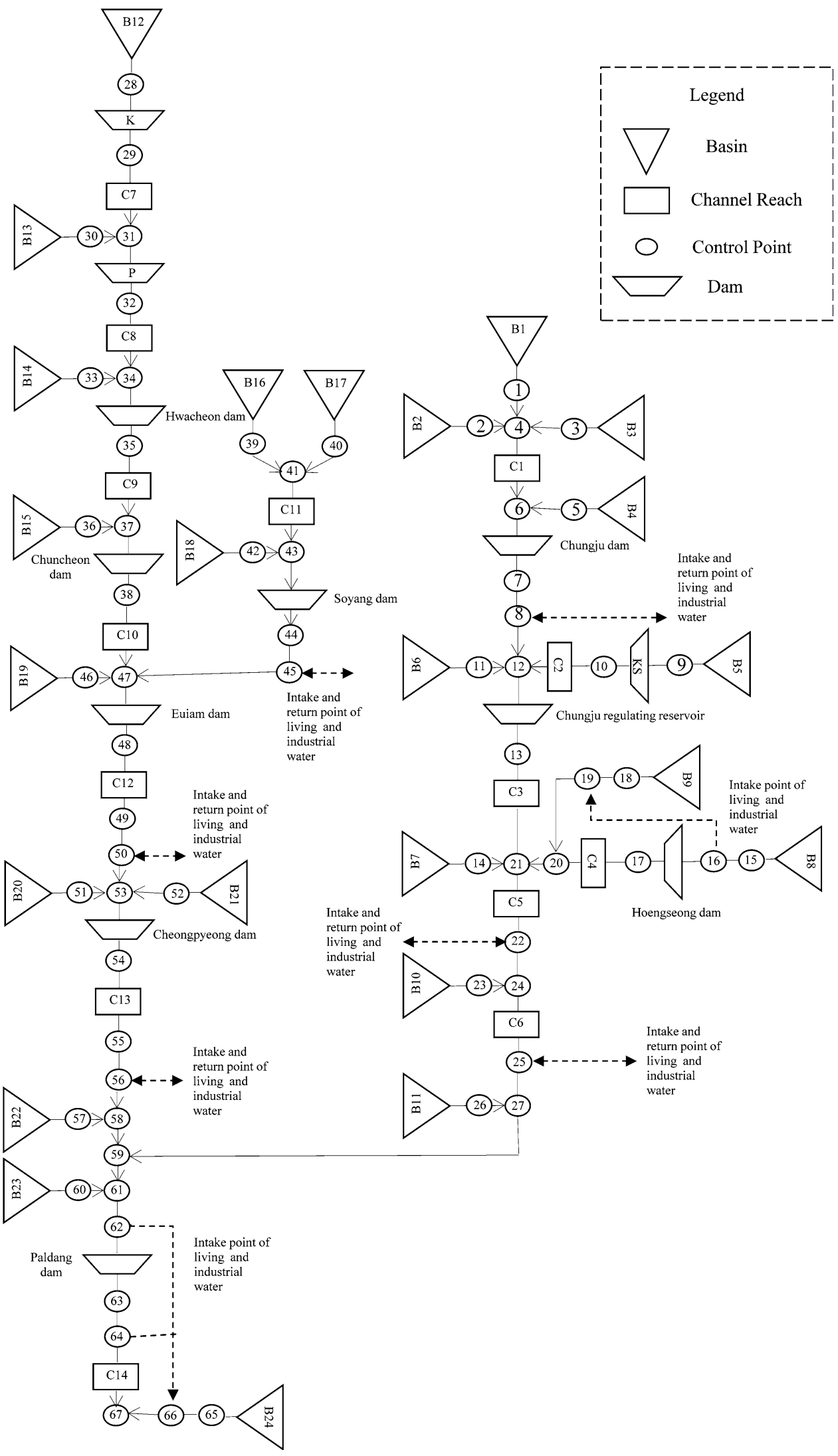


Table 1 Reference value for sensitivity analysis of parameters

\begin{tabular}{|c|c|c|c|c|c|c|c|c|}
\hline \multicolumn{9}{|l|}{ SMI } \\
\hline $\mathrm{SMI}(\mathrm{cm})$ & \multicolumn{2}{|l|}{0} & \multicolumn{2}{|l|}{1} & \multicolumn{2}{|l|}{2} & \multicolumn{2}{|l|}{999} \\
\hline Runoff percentage $(\%)$ & \multicolumn{2}{|l|}{15} & \multicolumn{2}{|l|}{53} & \multicolumn{2}{|l|}{100} & \multicolumn{2}{|l|}{100} \\
\hline \multicolumn{9}{|l|}{ BII } \\
\hline BII (cm/day) & 0.0 & 1.0 & 1.5 & 2.0 & 2.5 & 3.0 & 5.0 & 100.0 \\
\hline $\mathrm{BFP}(\%)$ & 44 & 16 & 14 & 12 & 11 & 10 & 10 & 10 \\
\hline \multicolumn{9}{|c|}{ BIITS: 40 h, BIIMX: $3 \mathrm{~cm} /$ day, BFLIM: $0.13 \mathrm{~cm} / \mathrm{h}$} \\
\hline \multicolumn{9}{|l|}{ S-SS } \\
\hline Input rate $(\mathrm{cm} / \mathrm{h})$ & 0.0 & 0.5 & 1.0 & 1.5 & 2.0 & 2.5 & 3.0 & \\
\hline Surface rate $(\mathrm{cm} / \mathrm{h})$ & 0.00 & 0.19 & 0.68 & 1.18 & 1.68 & 2.18 & 2.68 & \\
\hline \multicolumn{9}{|l|}{ PBLZ } \\
\hline \multicolumn{9}{|l|}{$50 \%$} \\
\hline \multicolumn{9}{|l|}{$T_{\mathrm{s}}(\mathrm{h})$} \\
\hline Surface: 3 , subsurface: & ow: & zo & & & & & & \\
\hline
\end{tabular}

presented in Appendix D of the SSARR manual are shown in Table 3.

Considering that the size of sub-basin area Number 17 is $1.084 .3-\mathrm{km}^{2}$ wide, and the domestic basins are mostly mountainous and more sloping than that of the United States, we can guess that the values of parameters are closer to Basin A than Basin B. In order to simplify the problem, we first fixed the number of possible reservoirs: four in the surface flow, which is the same as Basin A in Table 3 for the whole basins as well as sub-basin Number 17 ; three in the subsurface flow and two in baseflow and LZ. Under this circumstance, we performed the sensitivity analysis, changing each $T_{\mathrm{s}}$ for four flow fields in sub-basin Number 17. Generally, the shorter $T_{\mathrm{s}}$ becomes, the greater the peak flow and the quicker the peak time.

With respect to the surface flow, we also looked into the changes in hydrological flow curve thereby changing $T_{\mathrm{s}}$ at an interval of $2-4 \mathrm{~h}$. We presented this as results of the sensitivity analysis shown in Table 2 . These indicate that there was a decrease in peak flow at $12.0 \mathrm{~m}^{3} / \mathrm{s}$ at high water level. There were greater values of sensitivity at low water level than at high. Meanwhile, it is possible to set $T_{\mathrm{s}}$ at a basin as a function of flow without setting it as a constant. This causes $T_{\mathrm{s}}$ to decrease as the flow increases, which makes the results correspond to actual phenomena. The results that we used as input data by setting $T_{\mathrm{s}}$ of surface flow as a function of flow are as shown in Fig. 4. As for subsurface flow, we simulated the two cases both with $T_{\mathrm{s}}$ at an interval of $2 \mathrm{~h}$ from 8 to $12 \mathrm{~h}$ consistently and where $T_{\mathrm{s}}$ was set as a function of flow. This is shown in Fig. 5. The changes are similar to the surface flow both at high and low water levels. We checked the baseflow and LZ only where the $T_{\mathrm{s}}$ was constant. The results indicated that the sensitivity in baseflow was considerably high while that in the LZ was not low, as shown in Table 2. The effects on peak flow were very small, though there was a slight increase in underground water, having $T_{\mathrm{s}}$ at $50 \mathrm{~h}$.

River channel routing parameters consist of a number of virtual reservoirs, $\mathrm{n}$ and KTS. We presented the reference value in Table 1 under the condition that $n$ is 0.2 . Like the sensitivity analysis of basin routing, we performed the sensitivity analysis of $\mathrm{n}$ and KTS under the condition that the number of virtual reservoirs is fixed. We presented the results of the sensitivity analysis in Table 4 where all the conditions are the same as those in Table 1. The scope of $n$ is known to be between -1.0 and 1.0. Where the $n$ value has a minus value, flow may decrease as we go down stream basins because storage time increases as flow increases. Even though we have to decrease the $n$ value to reduce peak flow when going down stream basins, there was much decrease in peak flow as the $n$ value is less than 0 , as shown in Table 4, except where the $n$ value was 0 in which storage time becomes irrelevant with the amount of flow. We also presented the change in peak flow in Table 5 when taking $10,50,100$, and $200 \%$ of KTS rates calculated under the condition that $\mathrm{n}$ value was 0.2 . This explains why the change of peak flow was extremely small within $1 \%$ when KTS decreased despite the fact that the peak flow decreased according to the increase of KTS. Also, at some points there was a phenomenal increase of peak flow.

We could obtain the following conclusions through the sensitivity analysis of parameters as stated above. SMI, BII, and S-SS were all sensitive when both at high and low water levels among parameters related to basin routing, and where $T_{\mathrm{s}}$ for surface and subsurface flow is set as a function of flow, they showed sensitive results especially at high water levels, as well as at a low level compared with when it is fixed as a constant. S-SS, PBLZ, and $T_{\mathrm{s}}$ for baseflow were confirmed as a sensitive parameter at low water levels. 
Table 2 Sensitivity analysis for parameters

\begin{tabular}{|c|c|c|c|c|c|}
\hline \multirow[t]{2}{*}{ Parameter } & \multirow[t]{2}{*}{ Case } & \multicolumn{2}{|l|}{ High water level } & \multicolumn{2}{|l|}{ Low water level } \\
\hline & & Peak flow $\left(\mathrm{m}^{3} / \mathrm{s}\right)$ & Sensitivity & Flow of direct runoff end $\left(\mathrm{m}^{3} / \mathrm{s}\right)$ & Sensitivity \\
\hline \multirow[t]{3}{*}{ SMI } & SMI1 & 960.0 & 0.02 & 62.9 & 0.02 \\
\hline & SMI2 & 962.0 & & 63.0 & \\
\hline & SMI3 & 963.0 & & 63.1 & \\
\hline \multirow[t]{3}{*}{ BII } & BII1 & 961.0 & 0.01 & 62.1 & 0.17 \\
\hline & BII2 & 962.0 & & 63.0 & \\
\hline & BII3 & 962.0 & & 64.0 & \\
\hline \multirow[t]{3}{*}{ S-SS } & S-SS1 & 991.0 & 0.51 & 56.6 & 1.72 \\
\hline & S-SS2 & 962.0 & & 63.0 & \\
\hline & S-SS3 & 936.0 & & 68.7 & \\
\hline \multirow[t]{3}{*}{ BIITS (h) } & 30 & 968.0 & 0.03 & 62.0 & 0.06 \\
\hline & 40 & 962.0 & & 63.0 & \\
\hline & 50 & 957.0 & & 63.7 & \\
\hline \multirow[t]{3}{*}{ BIIMX (cm/day) } & 1 & 925.0 & 0.04 & 63.6 & 0.01 \\
\hline & 3 & 962.0 & & 63.0 & \\
\hline & 5 & 962.0 & & 63.0 & \\
\hline \multirow[t]{3}{*}{ BFLIM (cm/day) } & 0.08 & 962.0 & 0.00 & 63.0 & 0.00 \\
\hline & 0.13 & 962.0 & & 63.0 & \\
\hline & 0.18 & 962.0 & & 63.0 & \\
\hline \multirow[t]{3}{*}{ PBLZ (\%) } & 25 & 968.0 & 0.01 & 71.9 & 0.28 \\
\hline & 50 & 962.0 & & 63.0 & \\
\hline & 75 & 955.0 & & 54.1 & \\
\hline \multirow[t]{3}{*}{$T_{\mathrm{s}}($ surface $)(\mathrm{h})$} & 2 & 950.0 & 0.03 & 55.6 & 0.36 \\
\hline & 3 & 962.0 & & 63.0 & \\
\hline & 4 & 968.0 & & 70.8 & \\
\hline \multirow[t]{3}{*}{$T_{\mathrm{s}}($ subsurface) $(\mathrm{h})$} & 8 & 943.0 & 0.09 & 60.7 & 0.17 \\
\hline & 10 & 962.0 & & 63.0 & \\
\hline & 12 & 977.0 & & 65.0 & \\
\hline \multirow[t]{3}{*}{$T_{\mathrm{s}}$ (baseflow) } & 50 & 981.0 & 0.03 & 75.7 & 0.32 \\
\hline & 100 & 962.0 & & 63.0 & \\
\hline & 150 & 957.0 & & 56.9 & \\
\hline \multirow[t]{3}{*}{$T_{\mathrm{s}}($ lower zone) $(\mathrm{h})$} & 500 & 964.0 & 0.00 & 65.8 & 0.07 \\
\hline & 1,000 & 962.0 & & 63.0 & \\
\hline & 1,500 & 961.0 & & 62.0 & \\
\hline
\end{tabular}

Table 3 Basin routing parameters in the United States presented in the SSARR manual

\begin{tabular}{|c|c|c|c|c|}
\hline \multirow{2}{*}{$\begin{array}{l}\text { Basin: } \\
\text { Flow }\end{array}$} & \multicolumn{2}{|c|}{ A (area: $530 \mathrm{~km}^{2}$ ) } & \multicolumn{2}{|c|}{$\mathrm{B}$ (area: $6,250 \mathrm{~km}^{2}$ ) } \\
\hline & $\begin{array}{l}\text { Number of } \\
\text { possible } \\
\text { reservoirs }\end{array}$ & $T_{s}(\mathrm{~h})$ & $\begin{array}{l}\text { Number of } \\
\text { possible } \\
\text { reservoirs }\end{array}$ & $T_{s}(\mathrm{~h})$ \\
\hline Surface & 4 & 2.5 & 4 & 3.5 \\
\hline Subsurface & 3 & 11.0 & 3 & 26.0 \\
\hline Baseflow & 2 & 200.0 & 3 & 100.0 \\
\hline $\begin{array}{r}\text { Lower } \\
\text { zone }\end{array}$ & 2 & $2,000.0$ & 2 & $2,000.0$ \\
\hline
\end{tabular}

Determination and calibration of parameters using the SSARR model

Objective functions must first be selected so as to determine the values of final parameters. Also, it is necessary to minimize possible errors between observation flows and calculating ones as an objective function, and such errors can be classified as either "absolute errors" or "relative errors." However, the former may render low accuracy at low water level because it may determine the parameters that can decrease the errors during floods with much flow. Conversely, the latter may not reflect the flow at high water 
Fig. 4 Sensitivity for surface storage time as a function of flow
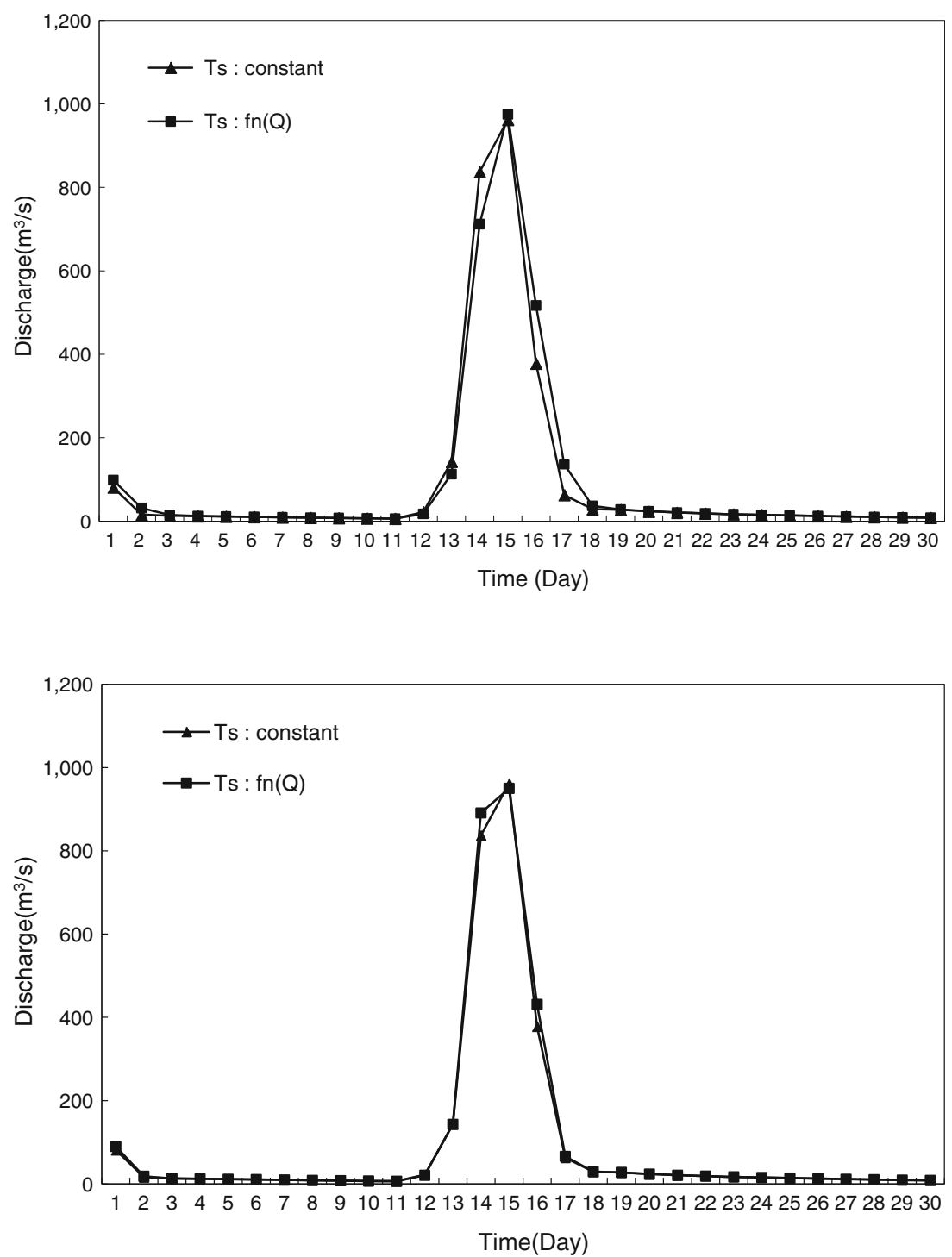

Fig. 5 Sensitivity for baseflow storage time as a function of flow
Table 4 Sensitivity analysis for $n$

\begin{tabular}{|c|c|c|c|c|c|c|c|c|}
\hline \multirow[t]{3}{*}{ Control point } & \multirow[t]{3}{*}{ Observed peak flow $\left(\mathrm{m}^{3} / \mathrm{s}\right)$} & \multicolumn{7}{|c|}{ Simulated peak flow $\left(\mathrm{m}^{3} / \mathrm{s}\right)$} \\
\hline & & \multicolumn{7}{|l|}{$n$} \\
\hline & & -0.1 & 0.0 & 0.1 & 0.2 & 0.3 & 0.4 & 0.5 \\
\hline Soyang & 1,657 & 647 & 1,170 & 876 & 1,100 & 1,130 & 1,130 & 1,130 \\
\hline Chungju & 1,587 & 1,150 & 1,740 & 1,580 & 1,680 & 1,670 & 1,670 & 1,670 \\
\hline Chungju RR & 933 & 1,580 & 2,370 & 1,960 & 2,020 & 2,050 & 2,050 & 2,270 \\
\hline Hoengseong & 422 & 271 & 271 & 271 & 271 & 271 & 271 & 271 \\
\hline Hwacheon & 1,894 & 1,830 & 2,090 & 1,970 & 2,000 & 2,050 & 2,050 & 2,080 \\
\hline Chuncheon & 1,840 & 1,910 & 2,690 & 2,250 & 2,330 & 2,440 & 2,440 & 2,600 \\
\hline Euiam & 2,066 & 2,340 & 3,840 & 3,110 & 3,500 & 3,510 & 3,510 & 3,740 \\
\hline Cheongpyeong & 3,924 & 2,630 & 5,360 & 3,650 & 4,400 & 4,830 & 4,830 & 5,230 \\
\hline Paldang & 5,585 & 3,920 & 7,700 & 4,430 & 5,760 & 6,700 & 6,700 & 7,440 \\
\hline
\end{tabular}

$R R$ regulating reservoir 
Table 5 Sensitivity analysis for KTS

\begin{tabular}{|c|c|c|c|c|c|c|}
\hline \multirow[t]{2}{*}{ Control point } & \multirow[t]{2}{*}{ Observed peak flow $\left(\mathrm{m}^{3} / \mathrm{s}\right)$} & \multicolumn{5}{|c|}{ Simulated peak flow $\left(\mathrm{m}^{3} / \mathrm{s}\right)$} \\
\hline & & $\mathrm{KTS} \times 0.1$ & $\mathrm{KTS} \times 0.5$ & $\mathrm{KTS} \times 1.0$ & $\mathrm{KTS} \times 1.5$ & $\mathrm{KTS} \times 2.0$ \\
\hline Soyang & 1,657 & 1,130 & 1,130 & 1,100 & 932 & 769 \\
\hline Chungju & 1,587 & 1,690 & 1,670 & 1,680 & 1,650 & 1,500 \\
\hline Chungju RR & 933 & 2,320 & 2,120 & 2,020 & 2,020 & 1,890 \\
\hline Hoengseong & 422 & 271 & 271 & 271 & 271 & 271 \\
\hline Hwacheon & 1,894 & 2,080 & 2,050 & 2,000 & 1,960 & 1,970 \\
\hline Chuncheon & 1,840 & 2,640 & 2,440 & 2,330 & 2,270 & 2,240 \\
\hline Euiam & 2,066 & 3,780 & 3,510 & 3,500 & 3,280 & 2,960 \\
\hline Cheongpyeong & 3,924 & 5,280 & 4,880 & 4,400 & 4,020 & 3,480 \\
\hline Paldang & 5,585 & 7,550 & 6,820 & 5,760 & 4,900 & 4,260 \\
\hline
\end{tabular}

$R R$ regulating reservoir

Table 6 Value of soil moisture index-runoff percent (SMI-ROP)

\begin{tabular}{|c|c|c|c|c|c|}
\hline SMI (cm) & $\begin{array}{l}\text { ROP (\%) } \\
\text { SMI-a }\end{array}$ & $\mathrm{SMI}(\mathrm{cm})$ & $\begin{array}{l}\text { ROP (\%) } \\
\text { SMI-b }\end{array}$ & $\mathrm{SMI}(\mathrm{cm})$ & $\begin{array}{l}\text { ROP (\%) } \\
\text { SMI-c }\end{array}$ \\
\hline 0 & 15 & 0 & 23 & 0 & 9 \\
\hline 1 & 53 & 0.3 & 55 & 1 & 25 \\
\hline 2 & 65 & 0.5 & 99 & 2 & 50 \\
\hline 3 & 100 & 1 & 100 & 3 & 70 \\
\hline \multirow[t]{4}{*}{999} & 100 & 999 & 100 & 4 & 90 \\
\hline & & & & 5 & 99 \\
\hline & & & & 10 & 100 \\
\hline & & & & 999 & 100 \\
\hline
\end{tabular}

level because it determines parameters in favor of the low level of water. Therefore, in choosing objective functions, we divided them when at high and low water levels because we thought an independent correcting procedure is most reasonable through sensitive parameters selected for each case such as with high and low levels of water. In other words, we chose as an objective function the one that minimizes the relative errors for annual maximum flow at nine controlling points through SMI, BII, S-SS, and $T_{\mathrm{s}}$ in the basin with high water level. When water level is low, we selected the minimization of average absolute errors in flow, which was less than a topographical amount for each point at nine controlling points in favor of the term when baseflow continues through BII, PBLZ, and $T_{\mathrm{s}}$ in baseflow. In this study, we determined parameters trial and error according to the established correcting methods and sensitivity analysis only on the basis of the flow data from the nine controlling points.

We fixed the remaining parameters as the first established reference value except for the SMI, BII, S-SS, $T_{\mathrm{s}}$ for each flow and PBLZ, which has high sensitivity both at high and low water levels among the internally treated parameters according to the correcting direction and the results of the sensitivity analysis from the 2001 and 2002 data. Furthermore, we determined the values as shown in Tables 6, 7, and 8 through some trials and errors considering the results at low water level for SMI, BII, S-SS, and $T_{\mathrm{s}}$ set as a function of flow, which have a great effect on peak flow. In Table 6, SMI-a is a curve for the sub-basin Numbers 12, 13, 14, and 16 whose $\mathrm{CN}$ value are less than 59; SMI-b, on the other hand, is for sub-basin Numbers 5, 7, 8, 9, 15, 18, 20, 21, 22, and 23 whose CN value are 60-69; while SMI-c is for the remaining sub-basins whose $\mathrm{CN}$ value are more than 70 . We determined BII, PBLZ, baseflow $T_{\mathrm{s}}$, and LZ $T_{\mathrm{s}}$ through trial and error considering the results at high water level even in correcting procedure at low levels of water. Moreover, we presented the final BII in Table 9, and also did 75\% of PBLZ, 150 and 1,500 $\mathrm{h}$ of $T_{\mathrm{s}}$ in baseflow and LZ.

For instance, the analysis results from the Soyang, Cheongpyeong, and Paldang by final parameters are featured in Figs. 6, 7, and 8. We presented errors at high levels of water in Tables 10 and 11, and errors at low levels in Table 12. According to this, errors at high water level decreased mainly in control points in the upper basin, and all those at low level decreased as shown by the 2001 and 2002 data. 
Table 7 Value of surface-subsurface separation (S-SS)

\begin{tabular}{llll}
\hline Input rate $(\mathrm{cm} / \mathrm{h})$ & \multicolumn{4}{l}{ Surface rate $(\mathrm{cm} / \mathrm{h})$} \\
\cline { 2 - 4 } & S-SS-a & S-SS-b & S-SS-c \\
\hline 0.0 & 0.00 & 0.00 & 0.00 \\
0.5 & 0.15 & 0.09 & 0.05 \\
1.0 & 0.65 & 0.58 & 0.47 \\
1.5 & 1.15 & 1.08 & 0.97 \\
2.0 & 1.65 & 1.58 & 1.47 \\
2.5 & 2.15 & 2.08 & 1.97 \\
3.0 & 2.65 & 2.58 & 2.47 \\
\hline
\end{tabular}

Table 8 Value of storage time $\left(T_{\mathrm{s}}\right)$ according to flow

\begin{tabular}{lc}
\hline Flow $\left(\mathrm{m}^{3} / \mathrm{s}\right)$ & $T_{\mathrm{s}}(\mathrm{h})$ \\
\hline 0 & 13 \\
10 & 11 \\
15 & 10 \\
20 & 9 \\
40 & 8 \\
100 & 7 \\
400 & 6 \\
1000 & 5 \\
\hline
\end{tabular}

Table 9 Value of baseflow infiltration index-baseflow percent (BII-BFP)

\begin{tabular}{llll}
\hline BII $(\mathrm{cm} /$ day $)$ & \multicolumn{3}{l}{ BFP $(\%)$} \\
\cline { 2 - 4 } & BII-a & BII-b & BII-c \\
\hline 0.0 & 40 & 42 & 35 \\
1.0 & 14 & 15 & 13 \\
1.5 & 12 & 13 & 11 \\
2.0 & 11 & 11 & 10 \\
2.5 & 10 & 10 & 10 \\
3.0 & 10 & 10 & 10 \\
5.0 & 10 & 10 & 10 \\
100.0 & 10 & 10 & 10 \\
\hline
\end{tabular}

\section{Verification of the SSARR model}

In order to verify the model, we simulated the runoff from other years using the parameter values determined through corrections. We selected the model for the year 2000. For instance, the results from the Soyang, Cheongpyeong, and Paldang are featured in Figs. 9, 10, and 11. Furthermore, we presented in Table 13 the relative errors at high water levels and absolute errors at low levels while comparing the simulated flow with the observed flow at the nine controlling points. Verification results at high water level indicate that they are satisfactory because the mean value of the relative errors appeared to be similar to that of the correction data. Even the verification results at low level were not so big in terms of the absolute errors, and all the errors at the nine points considerably improved compared to the correction data. Therefore, the verification results at the nine points of the Han River Basin were generally satisfactory both at high and low water levels.

Analysis of annual water balance

The SSARR model applied in this study adopted the IS Basin Model instead of the DC version that has been applied ever since as the latest version (Y2K). IS Basin Model not only contains all the functions of the DC model but also complements many functions related to long-term runoff interpretation, and so it has improved the simulating functions for interception, long-term functions of routing of LZ and the simulating functions of evapotranspiration.

The SSARR model especially provided output data related to the analysis of water balance. Simulation results in 2000 clearly presented calculated values of monthly water balance in each area as forms of precipitation, interception loss, evapotranspiration, and flow. From the above data, we presented the results in Table 14, changing the results by length $(\mathrm{cm})$ into the unit of volume $\left(\mathrm{m}^{3}\right)$, considering the size of the basin to obtain the annual water balance. In $2000,39.1 \%$ of total rainfalls were lost due to interception and evapotranspiration, and direct runoff and base runoff amounted for 51.7 and $15.2 \%$, respectively. The reason why the total sum of loss and runoff exceeds the total sum of rainfall is because long storage time of routing of LZ affected both the preceding and the succeeding years.

\section{Conclusion}

This study used the SSARR model to create the runoff model as an accompanying procedure for joint operation of dams required to effectively secure and manage water resources from the Han River Basin.

We selected the SSARR model as base model that can reflect the current status of water use and physical characteristics of upper dams in the Han River Basin. We classified the object, the Han River Basin, into 24 areas; collected precipitation data and basic hydrological data; calculated the size ratio of areas in the Han River Basin according to elevation, Thiessen coefficient and water duty, and returning rate; and made use of them as input data of the SSARR model. Among the parameters related to the basin routing, SMI, BII, and S-SS were all sensitive both at high and low water levels. They were sensitive especially at high water level as well as at low water level as 
Fig. 6 Result after calibration at Soyang point in the year 2001

Fig. 7 Result after calibration at Cheongpyeong point in the year 2001

Fig. 8 Result after calibration at Paldang point in the year 2001
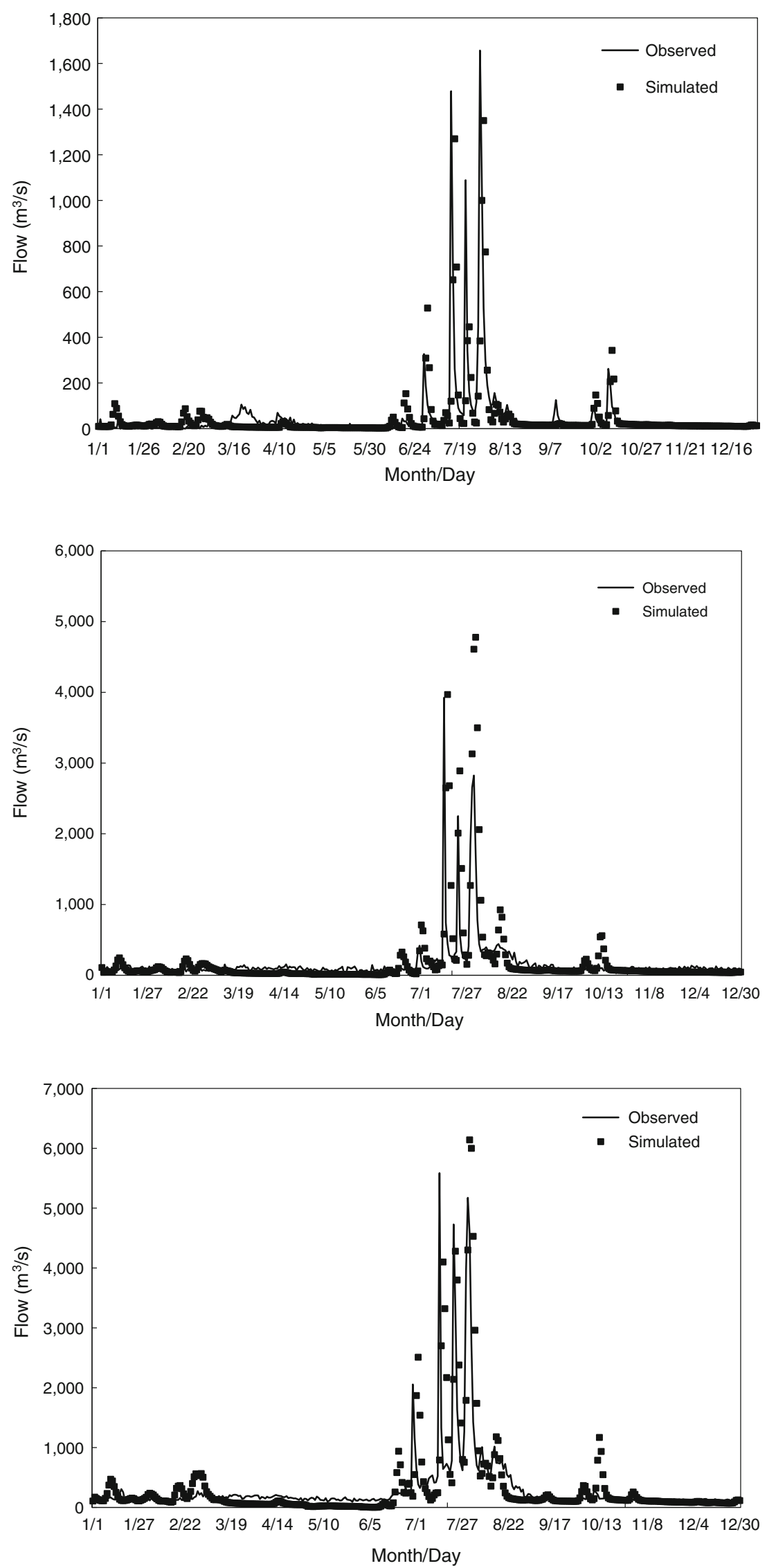
Table 10 Relative error before calibration at high water level

\begin{tabular}{|c|c|c|c|c|c|c|}
\hline \multirow[t]{2}{*}{ Control point } & \multicolumn{3}{|l|}{ Year 2001} & \multicolumn{3}{|l|}{ Year 2002} \\
\hline & $\begin{array}{l}\text { Observed } \\
\text { flow }\left(\mathrm{m}^{3} / \mathrm{s}\right)\end{array}$ & $\begin{array}{l}\text { Simulated } \\
\text { flow }\left(\mathrm{m}^{3} / \mathrm{s}\right)\end{array}$ & $\begin{array}{l}\text { Relative } \\
\text { error }(\%)\end{array}$ & $\begin{array}{l}\text { Observed } \\
\text { flow }\left(\mathrm{m}^{3} / \mathrm{s}\right)\end{array}$ & $\begin{array}{l}\text { Simulated } \\
\text { flow }\left(\mathrm{m}^{3} / \mathrm{s}\right)\end{array}$ & $\begin{array}{l}\text { Relative } \\
\text { error }(\%)\end{array}$ \\
\hline Soyang & 1,657 & 1,100 & 50.6 & 3,450 & 1,970 & 75.1 \\
\hline Chungju & 1,587 & 1,680 & 5.6 & 12,600 & 5,630 & 123.8 \\
\hline Chungju RR & 933 & 2,030 & 54.0 & 8,144 & 7,340 & 11.0 \\
\hline Hoengseong & 422 & 271 & 55.5 & 403 & 338 & 19.1 \\
\hline Hwacheon & 1,894 & 2,000 & 5.3 & 1,888 & 2,480 & 23.9 \\
\hline Chuncheon & 1,840 & 2,330 & 21.0 & 1,815 & 2,960 & 38.7 \\
\hline Euiam & 2,066 & 3,500 & 41.0 & 2,708 & 4,850 & 44.2 \\
\hline Cheongpyeong & 3,924 & 4,400 & 10.8 & 4,912 & 7,060 & 30.4 \\
\hline Paldang & 5,585 & 5,760 & 3.0 & 14,131 & 19,500 & 27.5 \\
\hline Mean & & & 27.4 & & & 43.7 \\
\hline
\end{tabular}

$R R$ regulating reservoir

Table 11 Relative error after calibration at high water level

\begin{tabular}{|c|c|c|c|c|c|c|}
\hline \multirow[t]{2}{*}{ Control point } & \multicolumn{3}{|l|}{ Year 2001} & \multicolumn{3}{|l|}{ Year 2002} \\
\hline & $\begin{array}{l}\text { Observed } \\
\text { flow }\left(\mathrm{m}^{3} / \mathrm{s}\right)\end{array}$ & $\begin{array}{l}\text { Simulated } \\
\text { flow }\left(\mathrm{m}^{3} / \mathrm{s}\right)\end{array}$ & $\begin{array}{l}\text { Relative } \\
\text { error }(\%)\end{array}$ & $\begin{array}{l}\text { Observed } \\
\text { flow }\left(\mathrm{m}^{3} / \mathrm{s}\right)\end{array}$ & $\begin{array}{l}\text { Simulated } \\
\text { flow }\left(\mathrm{m}^{3} / \mathrm{s}\right)\end{array}$ & $\begin{array}{l}\text { Relative } \\
\text { error }(\%)\end{array}$ \\
\hline Soyang & 1,657 & 1,350 & 22.7 & 3,450 & 2,420 & 42.5 \\
\hline Chungju & 1,587 & 1,870 & 15.2 & 12,600 & 6,100 & 106.5 \\
\hline Chungju RR & 933 & 2,220 & 58.0 & 8,144 & 7,930 & 2.7 \\
\hline Hoengseong & 422 & 394 & 7.0 & 403 & 381 & 5.6 \\
\hline Hwacheon & 1,894 & 2,350 & 19.4 & 1,888 & 2,910 & 35.1 \\
\hline Chuncheon & 1,840 & 3,120 & 41.0 & 1,815 & 3,500 & 48.1 \\
\hline Euiam & 2,066 & 4,030 & 48.7 & 2,708 & 5,950 & 54.5 \\
\hline Cheongpyeong & 3,924 & 5,230 & 25.0 & 4,912 & 8,780 & 44.1 \\
\hline Paldang & 5,585 & 6,750 & 17.3 & 14,131 & 22,000 & 35.8 \\
\hline Mean & & & 28.2 & & & 41.7 \\
\hline
\end{tabular}

$R R$ regulating reservoir

Table 12 Error at low water level (unit: $\mathrm{m}^{3} / \mathrm{s}$ )

$R R$ regulating reservoir

\begin{tabular}{lccccc}
\hline Control point & \multicolumn{2}{l}{ Before calibration } & & \multicolumn{2}{c}{ After calibration } \\
\cline { 2 - 3 } \cline { 5 - 6 } & Year 2001 & Year 2002 & & Year 2001 & Year 2002 \\
\hline Soyang & 2.4 & 5.7 & 1.8 & 3.7 \\
Chungju & 1.9 & 4.6 & & 1.1 & 4.7 \\
Chungju RR & 33.3 & 27.2 & 34.2 & 27.6 \\
Hoengseong & 0.4 & 0.1 & 0.1 & 0.1 \\
Hwacheon & 4.2 & 11.0 & 4.9 & 11.9 \\
Chuncheon & 0.9 & 12.8 & 0.0 & 14.5 \\
Euiam & 10.2 & 5.8 & 8.7 & 1.9 \\
Cheongpyeong & 6.2 & 4.4 & 8.4 & 10.3 \\
Paldang & 84.3 & 11.9 & 81.9 & 24.2 \\
Mean & 15.9 & & 15.7 & 11.2 \\
\hline
\end{tabular}


Fig. 9 Result of verification at Soyang point in the year 2000

Fig. 10 Result of verification at Cheongpyeong point in the year 2000

Fig. 11 Result of verification at Paldang point in the year 2000
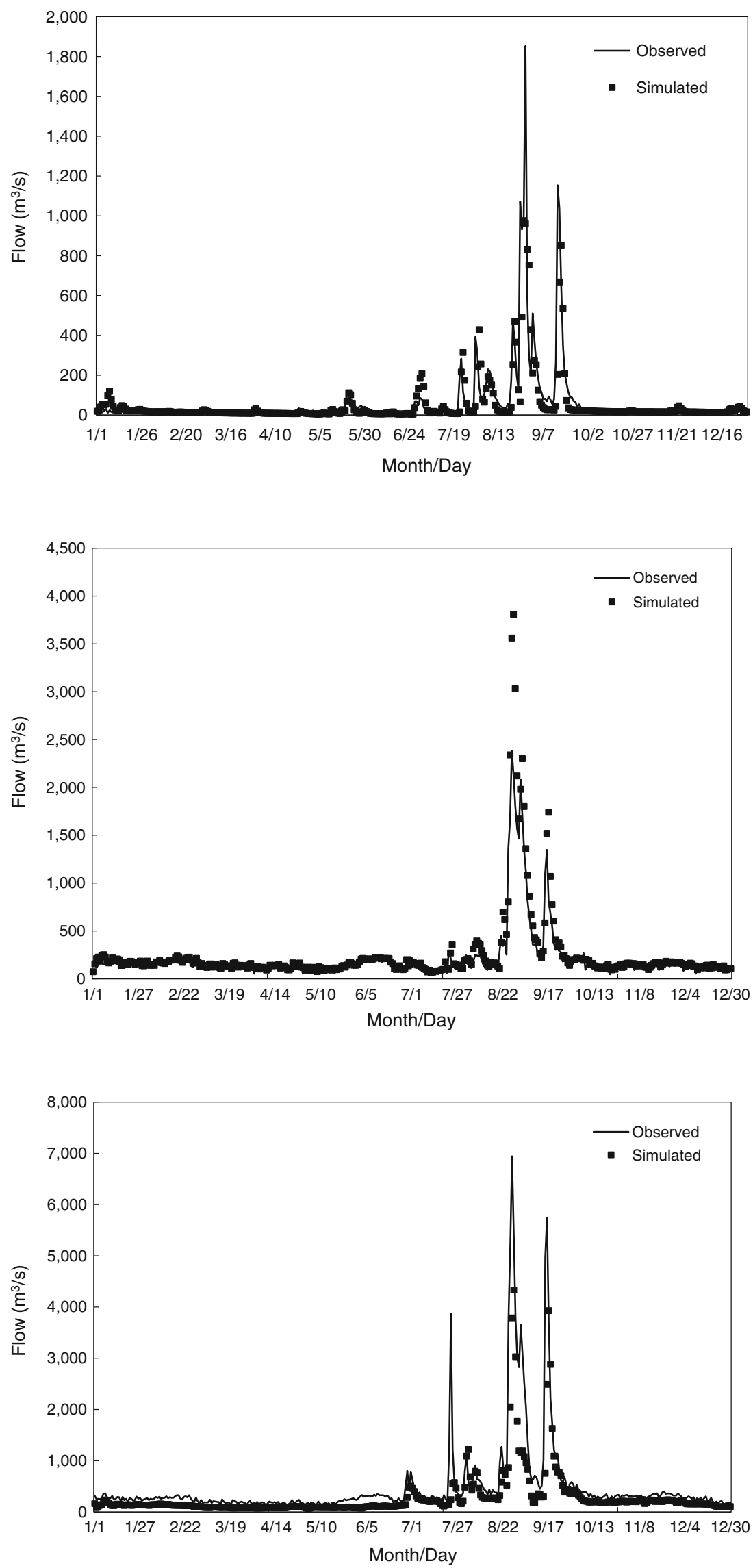
Table 13 Verification of the model in the year 2000

\begin{tabular}{|c|c|c|c|c|}
\hline \multirow[t]{2}{*}{ Control point } & \multicolumn{3}{|l|}{ Error at high water level } & \multirow{2}{*}{$\begin{array}{l}\text { Error at low water } \\
\text { level }\left(\mathrm{m}^{3} / \mathrm{s}\right)\end{array}$} \\
\hline & Observed flow $\left(\mathrm{m}^{3} / \mathrm{s}\right)$ & Simulated flow $\left(\mathrm{m}^{3} / \mathrm{s}\right)$ & Relative error (\%) & \\
\hline Soyang & 1,853 & 976 & 89.9 & 4.3 \\
\hline Chungju & 4,155 & 4,250 & 2.2 & 0.9 \\
\hline Chungju RR & 2,348 & 2,140 & 9.7 & 15.7 \\
\hline Hoengseong & 81 & 123 & 34.4 & 0.1 \\
\hline Hwacheon & 2,877 & 2,580 & 11.5 & 6.9 \\
\hline Chuncheon & 1,399 & 1,280 & 9.3 & 1.9 \\
\hline Euiam & 1,737 & 3,030 & 42.7 & 24.9 \\
\hline Cheongpyeong & 2,382 & 3,800 & 37.3 & 30.9 \\
\hline Paldang & 6,944 & 4,610 & 50.6 & 56.6 \\
\hline Mean & & & 32.0 & 15.8 \\
\hline
\end{tabular}

$R R$ regulating reservoir

Table 14 Water balance in the year 2000

\begin{tabular}{|c|c|c|c|c|c|c|c|c|c|}
\hline \multirow{2}{*}{$\begin{array}{l}\text { Number of sub- } \\
\text { basin }\end{array}$} & \multirow{2}{*}{$\begin{array}{l}\text { Area } \\
\left(\mathrm{km}^{2}\right)\end{array}$} & \multirow{2}{*}{$\begin{array}{l}\text { Precipitation } \\
\left(10^{8} \mathrm{~m}^{3}\right)\end{array}$} & \multirow{2}{*}{$\begin{array}{l}\text { Interception } \\
\left(10^{8} \mathrm{~m}^{3}\right)\end{array}$} & \multirow{2}{*}{$\begin{array}{l}\text { Evapotranspiration } \\
\left(10^{8} \mathrm{~m}^{3}\right)\end{array}$} & \multicolumn{5}{|c|}{ Runoff flow $\left(10^{8} \mathrm{~m}^{3}\right)$} \\
\hline & & & & & Surface & $\begin{array}{l}\text { Sub- } \\
\text { surface }\end{array}$ & Baseflow & $\begin{array}{l}\text { Lower } \\
\text { zone }\end{array}$ & Total \\
\hline 1 & $1,773.4$ & 21.25 & 5.07 & 5.44 & 0.84 & 8.12 & 0.61 & 1.98 & 11.55 \\
\hline 2 & $2,230.1$ & 25.50 & 6.13 & 6.28 & 1.09 & 10.53 & 0.71 & 2.32 & 14.65 \\
\hline 3 & 495.2 & 5.79 & 1.17 & 1.31 & 0.26 & 2.46 & 0.18 & 0.58 & 3.49 \\
\hline 4 & $1,892.4$ & 21.94 & 5.12 & 5.18 & 0.96 & 9.30 & 0.60 & 2.00 & 12.86 \\
\hline 5 & 676.5 & 8.89 & 1.64 & 0.49 & 0.95 & 4.68 & 0.41 & 1.35 & 7.39 \\
\hline 6 & 937.5 & 10.76 & 2.50 & 2.53 & 0.46 & 4.30 & 0.29 & 0.97 & 6.02 \\
\hline 7 & 571.0 & 7.49 & 1.64 & 0.36 & 0.79 & 3.88 & 0.31 & 1.03 & 6.02 \\
\hline 8 & 207.9 & 2.59 & 0.55 & 0.17 & 0.25 & 1.16 & 0.13 & 0.42 & 1.95 \\
\hline 9 & $1,283.1$ & 14.25 & 3.26 & 0.87 & 1.46 & 7.20 & 0.66 & 2.21 & 11.52 \\
\hline 10 & 776.9 & 9.72 & 1.77 & 2.56 & 0.42 & 4.22 & 0.31 & 1.01 & 5.95 \\
\hline 11 & $1,273.9$ & 12.94 & 2.79 & 3.80 & 0.50 & 4.91 & 0.38 & 1.42 & 7.19 \\
\hline 12 & $2,150.0$ & 22.08 & 5.25 & 3.90 & 3.31 & 7.82 & 0.71 & 2.56 & 14.40 \\
\hline 13 & 833.0 & 9.34 & 1.99 & 1.57 & 1.38 & 3.29 & 0.34 & 1.14 & 6.14 \\
\hline 14 & 813.8 & 7.41 & 1.88 & 1.38 & 1.00 & 2.38 & 0.24 & 0.89 & 4.51 \\
\hline 15 & 776.8 & 8.76 & 2.03 & 0.45 & 0.88 & 4.23 & 0.38 & 1.28 & 6.76 \\
\hline 16 & 927.8 & 7.31 & 2.04 & 0.60 & 1.10 & 2.65 & 0.28 & 1.00 & 5.03 \\
\hline 17 & $1,084.3$ & 8.58 & 2.80 & 0.55 & 0.40 & 3.83 & 0.31 & 1.06 & 5.60 \\
\hline 18 & 678.8 & 7.56 & 1.58 & 0.42 & 0.76 & 3.71 & 0.36 & 1.26 & 6.08 \\
\hline 19 & 280.8 & 2.72 & 0.48 & 0.70 & 0.13 & 1.18 & 0.07 & 0.29 & 1.67 \\
\hline 20 & $1,566.1$ & 17.15 & 3.68 & 1.04 & 1.72 & 8.32 & 0.81 & 2.77 & 13.62 \\
\hline 21 & 962.9 & 11.94 & 1.91 & 0.78 & 1.33 & 6.39 & 0.52 & 1.78 & 10.02 \\
\hline 22 & 399.1 & 4.41 & 0.78 & 0.31 & 0.47 & 2.18 & 0.20 & 0.67 & 3.51 \\
\hline 23 & 604.7 & 6.43 & 1.18 & 0.45 & 0.88 & 3.38 & 0.29 & 0.94 & 5.47 \\
\hline 24 & $2,506.6$ & 27.73 & 5.57 & 6.39 & 1.34 & 13.17 & 0.74 & 2.42 & 17.67 \\
\hline Summation & & 282.53 & 62.81 & 47.52 & 22.66 & 123.26 & 9.84 & 33.33 & 189.08 \\
\hline Ratio & & 100.00 & 22.23 & 16.82 & 8.02 & 43.63 & 3.48 & 11.80 & 66.92 \\
\hline
\end{tabular}

compared when they were fixed as a constant if $T_{\mathrm{s}}$ in surface flow and subsurface flow. At low water level, PBLZ and $T_{\mathrm{s}}$ in underground water including S-SS were determined to be sensitive parameters. In order to correct the forthcoming runoff model after the sensitivity analysis, the user has to control the peak part by changing SMI, BII, 
and S-SS, perform at low water, and delay time by changing the parameters in $T_{\mathrm{s}}$. We guessed the optimal parameter values by trial and error to minimize the errors between observed flows and simulated the ones at nine controlling points in the order of sensitive parameters. According to the analysis results of annual water balance provided by the SSARR model, $39.1 \%$ of the total amount was lost due to interception and evapotranspiration, $51.7 \%$ due to direct runoff, plus $15.2 \%$ to base runoff. There was a total of $66.9 \%$ runoff in 2000 .

The results of this study will be used as basic future data and technology for integrated water management of the Han River Basin.

Acknowledgments This research was conducted through a grant (Code \#1-6-3) from the Sustainable Water Resources Research Centre of the $21^{\text {st }}$-Century Frontier Research Program.

Open Access This article is distributed under the terms of the Creative Commons Attribution Noncommercial License which permits any noncommercial use, distribution, and reproduction in any medium, provided the original author(s) and source are credited.

\section{References}

An SJ, Lee YS (1989) Analysis of runoffs in river basins using SSARR. J Korea Water Resour Assoc 22(1):109-116 (in Korean)

Hwang MH, Maeng SJ, Lee SJ, Lee BS, Koh IH (2009) Discharge characteristics at the control point for rainfall runoff model application. J Int Comm Irrig Drain 58(4):429-444

Kim HY, Park SW (1988) Simulating daily inflow and release rates for irrigation reservoirs. J Korean Soc Agric Eng 30(1):50-62 (in Korean)
Korea Water Resources Corporation (KOWACO) (1996) Analysis Modeling Part, Development of Real-time Reservoir Operating System in Nakdong River, Daejeon, Korea (in Korean)

Korea Water Resources Corporation (KOWACO) (1997) Survey Report on Water Supply Ability Dams, Daejeon, Korea (in Korean)

Korea Water Resources Corporation (KOWACO) (2000) Development of a Continuous Stremflow Simulation Model, Daejeon, Korea (in Korean)

Korea Water Resources Corporation (KOWACO) (2004) Development of a Base Technology for Integrated Real-time Water Management System, Daejeon, Korea (in Korean)

Korea Water Resources Corporation (KOWACO) (2008) Analysis Modeling Part, Development of Real-time Reservoir Operating System in Han River, Daejeon, Korea (in Korean)

Ministry of Construction (MOC) (1988) Mid-term and Long-term Synthetic Disaster Prevention Plan, Gwacheon, Korea (in Korean)

Ministry of Construction and Transportation (MOCT) (2004a) Report on the Long-term Comprehensive Plan on Water Resources, Gwacheon, Korea (in Korean)

Ministry of Construction and Transportation (MOCT) (2004b) Survey Report on the Han River Basin, Gwacheon, Korea (in Korean)

National Weather Service (1996) Overview of NWSRFS, NWS River Forecast System User's Manual. National Weather Service, Section I1.1

Nelson ML, Rockwood DM (1971) Flood regulation by Columbia treaty projects. J Hydraul Div ASCE 797(HY1):7798-144-7798160

Park SW (1993) A tank model shell program for simulating daily streamflow from small watersheds. J Korea Water Resour Assoc 26(3):47-61 (in Korean)

Rockwood DM (1968) Application of stream flow synthesis and reservoir regulation (SSARR) program to the lower Mekong River. In Proceedings of the use of analog and digital computers in hydrology symposium, international association of scientific hydrology, UNESCO, pp 329-344

Sugawara M (1979) Automatic calibration of the tank model. Hydrol Sci Bull 24:375-388

U.S Army Corps of Engineers (USACE) (1991) SSARR Users' Manual. North Pacific Division, Portland, USA 